\title{
Description of Micropygomyia brandaoi sp. n. (Diptera: Psychodidae: Phlebotominae), a fossil phlebotomine from the Dominican Republic
}

\author{
José Dilermando Andrade Filho/ ${ }^{+}$, Eunice A Bianchi Galati', Alda Lima Falcão, \\ Reginaldo Peçanha Brazil ${ }^{2}$
}

\begin{abstract}
Laboratório de Leishmanioses, Instituto René Rachou-Fiocruz, Av. Augusto de Lima 1715, 30190-002 Belo Horizonte, MG, Brasil ${ }^{1}$ Departamento de Epidemiologia, Faculdade de Saúde Pública, Universidade de São Paulo, São Paulo, SP, Brasil Laboratório de Bioquímica, Fisiologia e Imunologia de Insetos, Instituto Oswaldo Cruz-Fiocruz, Rio de Janeiro, RJ, Brasil
\end{abstract}

The description of Micropygomyia brandaoi, a new species of fossil phlebotomine sand fly, is based on one male specimen obtained from Dominican amber of the Miocene period (20 million years). In this new species, the fifth palpal segment is long, the coxite lacks a setal tuft and the style shows four well-developed spines. This set of characters allowed us to place the new species in the genus Micropygomyia Barretto.

Key words: Micropygomyia brandaoi sp. n. - Phlebotominae - sand fly - Diptera - Psychodidae - taxonomy - fossil

Fossil phlebotomines have been discovered in amber from Mexico and the Dominican Republic (Quate 1963, Brazil \& Andrade Filho 2002, Andrade Filho \& Brazil 2004, Peñalver \& Grimaldi 2005, Andrade Filho et al. 2006a, b, 2007). Amber from the Dominican Republic has an estimated age of about 20 million years, and thus dates from the Miocene period (Iturralde-Vicente \& MacPhee 1966).

We examined 32 amber inclusions from Dominican Republic containing 55 phlebotomine sandflies specimens; all specimens were assumed to belong to a single undescribed species. A rectangular piece of amber, measuring $1.9 \mathrm{~cm} \times 1 \mathrm{~cm}$ was selected as holotype. We are herein describing a new species based only in the holotype. The measures are given in micrometers; measures were made using an Olympus $\mathrm{CH} 2$ microscope fitted with an ocular micrometer. Drawings were made using a camera lucida. The classification scheme used is that proposed by Galati (1995).

\section{Micropygomyia brandaoi sp. n. (Figs 1-3)}

Male holotype - Sand fly relatively small, measurement ca 1,456; its entire length could not be measured, and its general color could not be defined with precision. Paired appendages complete.

Head: laid on its side, thus obstructing the width measurement. Mouthparts not distinguishable, thus palpomeres 1st and 2nd could not be clearly separated; length of both palpomeres $=135$. Lengths of other palpomeres

Financial support: Capes, Fiocruz

+ Corresponding author: jandrade@cpqrr.fiocruz.br

Received: 12 December 2007

Accepted: 24 June 2008 as follows: $3 \mathrm{rd}=119 ; 4$ th $=72 ; 5$ th $=262$. Palpal formula 1.4.2.3.5, the length of palpomere 5th being longer than the sum of the length of palpomeres 3rd and 4th. Newstead's spines visible on 3rd palpomere, implanted nearly the middle. Antennae complete with ascoids clearly visible, these being simple and short, not reaching the apex of the subsequent flagellomere. Papilla present on AIII, AIV, AXIII-AXVI. Measurements of flagellomeres: AIII = 225; $\mathrm{AIV}=88 ; \mathrm{AV}=88 . \mathrm{AXV} / \mathrm{AXVI}$ ratio > 1.0. AIII/AIV ratio $=2,56: 1$ and $\mathrm{AIII} /$ palpomere 5 ration $=0,86: 1$.

Thorax: thoracic bristles not visible, except on the notum. Wings: 568 wide. Principal wing indices: $\alpha$ (R2) - 316; $\beta$ (R2 + R3) - 237; $\gamma(\mathrm{R} 2+\mathrm{R} 3+\mathrm{R} 4)$ - 248; $\delta$ (part of R1 that extends beyond the junction of R2+R3) 34. $\alpha / \beta$ ratio $=1.33: 1$ and $\alpha / \delta$ ratio $=9.29: 1$. Legs without special characters. Lengths of anterior, median and posterior femora 597, 597 and 642 respectively. Lengths of anterior, median and posterior tibiae 783, 879 and 992 respectively. Anterior, median and posterior tarsomeres 507, 541 and 597 respectively. Anterior femur/median femur ration $=1: 1$ and anterior femur/anterior tibia ratio $=0.76: 1$.

Abdomen: genital pump and genital filaments not visible. Aedeagus triangular; gonostyle 99 long, with four spines arranged as follows: one apical, one external superior, one external inferior implanted at same level as an internal spine on the middle of the gonostyle. Preapical bristle absent. Coxite 130 long, without bristles. Paramere 132 long, bearing a dorsal group of bristles. Lateral lobe 168 long and 19 wide. Lateral lobe/coxite ratio $=1.29: 1 ;$ coxite/paramere ratio $=0,98: 1 ;$ lateral lobe $/$ paramere ratio $=1.27: 1$.

Type material - Holotype male and 54 paratypes males, Dominican Republic, North Santiago, specimen in amber from the mid-Miocene period, deposited in the Phlebotomine Sand Fly collection of the Instituto René Rachou-Fiocruz, Belo Horizonte, MG, Brazil.

Etymology - The name Micropygomyia brandaoi sp. n. is in honor of Sinval Pinto Brandão Filho, for his contribution to the knowledge on leishmaniasis in Brazil. 


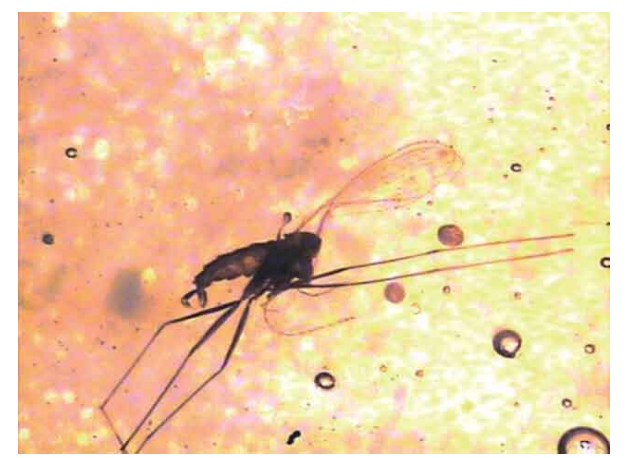

Fig. 1: Micropygomyia brandaoi sp. n. General aspect in amber.

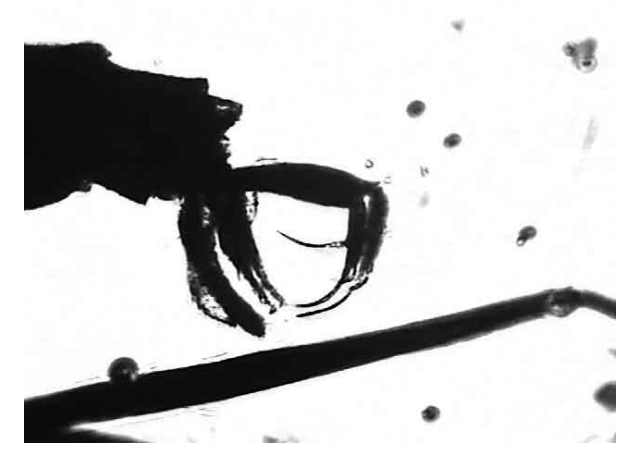

Fig. 2: Micropygomyia brandaoi sp. $\mathrm{n}$. Terminalia

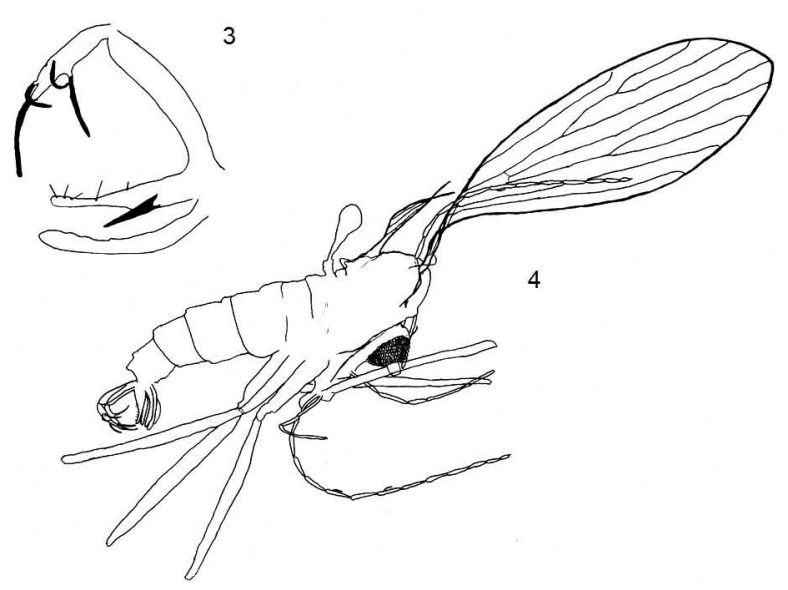

Figs 3-4: Micropygomyia brandaoi sp. nov. 3: terminália; 4: general aspect.

\section{TAXONOMIC DISCUSSION}

The presence of short ascoid, palpomere 5th longer than the others, small terminalia, four spines on gonostyle and gonocoxite without bristles allow the inclusion of Micropygomyia brandaoi sp. $\mathrm{n}$. in the genus Micropygomyia Barretto. In this genus, usually the 2 th palpomere is smaller or equal to the 4 th. However in the new species the opposite was observed; the same has been described to occur with some specimens belonging to the Micropygomyia cayennensis (Floch \& Abonnenc) complex.
The terminalia of $M$. brandaoi sp. n. is very similar to that of the members of the Micropygomyia cayennensis complex. According to Young and Duncan (1994), the anterior femora in all subspecies of $M$. cayennensis is shorter than the anterior tibiae. However in five specimens of $M$. cayennensis cayennensis (numbers 3759, 6178, 55882 and 55883) as well as in a M. cayennensis hispaniolae (Fairchild \& Trapido) paratype examined by us, the anterior femur was always longer than the anterior tibia, which ratio in $M$. c. cayennensis specimen 3759 and $M$. c. hispaniolae being $1.02: 1$. In M. brandaoi sp. n. this ratio is $0.75: 1$; the anterior femur thus being much shorter than the anterior tibia. The $\mathrm{a} / \mathrm{b}$ ratio in those two subspecies are 1.78:1 and $1.77: 1$ respectively, while in this fossil species this ratio is 9.58:1. In M. brandaoi sp. n. the lateral lobe is longer than both the paramere and the gonocoxite, the lateral lobe/paramere and lateral lobe/basistyle ratios are 1.25:1 and 1.07:1, respectively. In $M$. c. cayennensis these ratios are only $0.78: 1$ and $0.69: 1$ respectively, while in M. c. hispaniolae they are $0.69: 1$ and $0.85: 1$. The gonostyle of M. brandaoi sp. n. also differs from that of species of the $M$. cayennensis complex. The external superior spine is implanted at some distance from the apex of gonostyle in M. brandaoi sp. n., while in M. cayennensis complex this spine is very close the apex. Given all these differences we concluded that the new species does not belong to the M. cayennensis complex.

The arrangement of the spines in the gonostyle is like that found in Micropygomyia atroclavata (Knab) and Micropygomyia venezuelensis (Floch \& Abonnenc); however these species have tuft of bristles in gonostyle, absent in the new fossil species $M$. brandaoi sp. n. This characteristic distinguishes $M$. brandaoi sp. n. from those species belonging to subgenus Coquillettimyia. Thus, we do not include the new fossil species in any subgenus of genus Micropygomyia.

The small terminalia, especially with respect to length of lateral lobe, paramere and gonocoxite distinguish M. brandaoi sp. n. from the other sand fly fossils species.

\section{REFERENCES}

Andrade Filho JD, Brazil RP, Falcão AL, Galati EAB 2007. Description of Pintomyia (Pifanomyia) paleotrichia, a Miocene period new species from the Dominican Republic (Diptera: Psychodidae: Phlebotominae). Mem Inst Oswaldo Cruz 102: 901-903.

Andrade Filho JD, Falcão AL, Brazil RP 2004. A new phlebotomine fossil species Trichopygomyia killickorum sp. n. (Diptera: Psychodidae), found in the Dominican Republic amber. Parasite 11: 71-73.

Andrade Filho JD, Falcão AL, Galati EAB, Brazil RP 2006a. Pintomyia (Pifanomyia) paleotowsendi, a new sand fly from the Miocene amber of Dominican Republic (Diptera: Psychodidae: Phlebotominae). Mem Inst Oswaldo Cruz 101 (Suppl. II): 57-58.

Andrade Filho JD, Galati EAB, Falcão AL 2006b. Description of Pintomyia (Pifanomyia) brazilorum sp. nov. a new fossil species from the Dominican Republic (Diptera: Psychodidae: Phlebotominae). Mem Inst Oswaldo Cruz 101: 141-142.

Brazil RP, Andrade Filho JD 2002. Description of Pintomyia (Pifanomyia) falcaorum sp. n. (Diptera: Psychodidae: Phlebotominae) a fossil sand fly from Dominican amber. Mem Inst Oswaldo Cruz 97: 501-503. 
Galati EAB 1995. Phylogenetic systematics of Phlebotominae (Diptera: Psychodidae) with emphasis on American groups. Bol Dir Malariol Saneam Amb 35 (Supl. 1): 133-142.

Iturralde-Vinent MA, MacPhee RDE 1996. Age and Paleogeographical origin of Dominican amber. Scien 273: 1850-1852.

Peñalver E, Grimaldi D 2005. Assemblages of mammalian hair and blood-feeding midges (Insecta: Diptera: Psychodidae: Phlebotomi- nae) in Miocene amber. Trans R Soc Edin Earth Sci 96: 177-195.

Quate LW 1963. Fossil Psychodidae in Mexican amber, part 2 Diptera: Insect J Paleontol 37: 110-118.

Young DG, Duncan MA 1994. Guide to the Identification and Geographic Distribution of Lutzomyia Sand Flies in Mexico, the West Indies, Central and South America (Diptera: Psychodidae). Mem Am Entomol Inst 54, Associated Publishers, 881 pp. 